\title{
Delavnica o nadzoru lesenega pakirnega materiala
}

\section{Andreja KAVČIČ}

30. septembra 2015 je v Hotelu Roškar v Hajdini potekala delavnica o nadzoru lesenega pakirnega materiala (v nadaljevanju LPM), ki jo je organizirala Uprava za varno hrano, veterinarstvo in varstvo rastlin (UVHVVR), Sektor za zdravje rastlin in rastlinski semenski material. Delavnice se je udeležilo približno 40 predstavnikov različnih organizacij, poleg predstavnikov UVHVVR (organizatorji dogodka in fitosanitarni inšpektorji), še predstavniki Gozdarskega inštituta Slovenije, Zavoda za gozdove Slovenije, Kmetijskega inštituta Slovenije, Biotehniške Fakultete Univerze v Ljubljani ter Inštituta za hmeljarstvo in pivovarstvo Slovenije. Dogodek je vodila mag. Katarina Groznik (UVHVVR).

V uvodu je mag. Erika Orešek (UVHVVR) predstavila evropsko zakonodajo $\mathrm{v}$ zvezi $\mathrm{z}$ lesenim pakirnim materialom. LPM se splošno uporablja $v$ mednarodnem prometu $\mathrm{z}$ različnim blagom in predstavlja veliko tveganje za vnos in širjenje škodljivih organizmov za rastline. Z namenom preprečevanja vnosa in širjenja karantenskih škodljivih organizmov je EU leta 2005 uvedla posebne fitosanitarne zahteve pri uvozu pošiljk, ki so opremljene z LPM. Z direktivo Evropske Komisije 2004/102/ES o varstvenih ukrepih proti vnosu organizmov, škodljivih za rastline ali rastlinske proizvode, $\mathrm{v}$ Skupnost in proti njihovemu širjenju v Skupnosti, ki med drugim ureja tudi promet $\mathrm{z}$ LPM, je bil v evropsko zakonodajo implementiran mednarodni fitosanitarni standard št. 15 (ISPM-15), ki določa, da mora biti LPM, ki je narejen iz neobdelanega lesa in se uporablja v mednarodnem prometu, ustrezno obdelan in označen $\mathrm{v}$ skladu s tem standardom. Zahteve pri uvozu blaga, ki ga spremlja LPM, v EU veljajo za vse tretje države, razen Švice, pri premeščanju znotraj EU pa samo za območja, kjer je v preteklosti prišlo do izbruhov nevarnih karantenskih škodljivcev azijskega kozlička (Anoplophora glabripennis) in borove ogorčice (Bursaphelenchus xylophilus). Zaradi pojava več nevarnih karantenskih vrst in izbruhov azijskega kozlička v nekaterih državah EU v preteklih letih, ki so bili posledica vnosa z LPM, ki je spremljal trgovsko blago s Kitajske, je bila obstoječa zakonodaja dopolnjena z Izvedbenim sklepom Komisije št. 2013/92/EU in Izvedbenim sklepom Komisije št. 2015/474/EU. Ta dva sklepa dodatno opredeljujeta obvezni carinski nadzor LPM, ki spremlja določene pošiljke s Kitajske, $\mathrm{z}$ namenom, da se prepreči vnos nevarnih škodljivcev, zlasti azijskega kozlička, z LPM na območje EU. Ob koncu uvoda nas je Vlasta Knapič (UVHVVR) na kratko seznanila še z novostmi ISPM15. Te se nanašajo na zamenjavo načina obdelave LPM z zaplinjevanjem z metilbromidom, ki je zaradi strupenosti v EU prepovedan že od leta 2010, z drugimi metodami, veljati pa bodo začele predvidoma aprila 2016.
Uvodu je sledilo predavanje g. Hannesa Krehana z Avstrijskega raziskovalnega centra za gozdove (Bundesfoschungszentrum für Wald, BFW), ki je na začetku udeležencem najprej nazorno predstavil azijskega kozlička, ki je nevaren karantenski škodljivec velikega števila drevesnih vrst. Vrsta izvira s Kitajske, vendar se zaradi globalne trgovine naglo širi $v$ druge dele sveta, tudi v Evropo. V EU je bil ta škodljivec vnesen že večkrat, predvsem z LPM pri uvozu kamna in kamnitih materialov s Kitajske. Do sedaj so se žarišča te vrste pojavila v Avstriji, Nemčiji, Italiji, Franciji, na Nizozemskem in v Združenem kraljestvu. Tej vrsti je zelo podoben kitajski kozliček (A. chinensis), še ena nevarna azijska vrsta, ki je bila tudi že najdena v naši neposredni bližini, v Italiji in na Hrvaškem. Vrsti sta skoraj identični po izgledu, imata zelo podobno biologijo in iste vrste gostiteljskih dreves. Po simptomatiki se razlikujeta predvsem v tem, kje na drevesu se pojavljajo simptomi napada. Pri azijskem kozličku se pojavljajo praviloma na zgornjem delu debel in v krošnji, pri kitajskem pa jih najdemo v spodnjem delu debla in $\mathrm{v}$ koreninah. Pri obeh vrstah sta glavna načina širjenja na nova področja s pomočjo LPM in s sadikami dreves.

Predavatelj nam je predstavil splošno biologijo azijskega kozlička ter poškodbe na drevju, ki jih povzročajo ličinke ter odrasli osebki in služijo kot pokazatelj prisotnosti vrste v gozdovih ali v urbanem okolju. Poudaril je, da je za preprečevanje vnosa in širjenja tega škodljivca na nova območja ključno redno pregledovanje dreves $\mathrm{V}$ območjih, kjer obstaja nevarnost pojava tega škodljivca, pri čemer je nujno dobro poznavanje simptomov, ki kažejo na prisotnost različnih razvojnih oblik. Poleg manj očitnih nekroz pod lubjem in galerij $\mathrm{v}$ lesu, so najbolj značilni pokazatelj prisotnosti te vrste okrogle, $10-15$ mm velike izhodne odprtine hroščev na skorji odmirajočih dreves, prisotnost žagovine neposredno ob odprtinah in na deblu ter mehanske poškodbe poganjkov zaradi objedanja, ki jih s prehranjevanjem povzročajo odrasli osebki. Pri preiskovanju pogosto najdejo tudi odrasle osebke. Odrasli hrošči merijo v dolžino $25 \mathrm{~mm}$ (samci) - $35 \mathrm{~mm}$ (samice), so bleščeče črni in imajo na pokrovkah približno 20 belih nepravilno oblikovanih peg. Imajo značilno dolge antene, ki so pri samcih 2,5-krat daljše kot je dolžina telesa, pri samicah pa 1,3-krat daljše kot je dolžina telesa ter so sestavljene iz 11 členov. Pregledovanje je vizualno, opravljajo pa ga za to posebej usposobljene osebe. Glede na to, da so simptomi, ki kažejo, da je drevo napadel azijski kozliček, prisotni predvsem v zgornjem delu debla in v krošnji, je pri pregledovanju nujna uporaba lestev ali dvigal. Izvedeli smo, da v Avstriji to delo opravljajo tudi posebej izšolani plezalci. Pri iskanju simptomov kozličkov na drevesih in pri pregledovanju LPM, so se kot zelo uspešni izkazali posebej izšolani psi. 
V nadaljevanju nam je natančneje predstavil primere izbruhov azijskega kozlička v Avstriji v letih 2001, 2012 in 2013. Izbruh leta $2001 \mathrm{v}$ mestu Braunau je bil hkrati prva uradna potrditev prisotnosti vrste v EU. Opisal je, kako je potekal celoten proces izkoreninjenja $\mathrm{v}$ vseh treh primerih ter ukrepe za preprečevanje vnosa in širjenja vrste, ki so sledili v naslednjih letih. Povedal je, da so v Avstriji za ukrepe izkoreninjenja odgovorne lokalne organizacije za varstvo rastlin, ki skupaj z ustreznimi raziskovalnimi ustanovami izdelajo načrt izkoreninjenja. V konkretnih primerih sta vizualnemu pregledu dreves oz. iskanju simptomov s psi sledila posek in uničenje (mletje, sežig) vseh napadenih dreves ter preventivni posek gostiteljskih dreves v neposredni bližini žarišča napada. Če drevesa niso bila uničena takoj, so jih prekrili $\mathrm{z}$ insekticidno mrežo Storanet $\AA$, da bi preprečili morebitno izletavanje hroščev v času do uničenja dreves. Kot najpogostejša gostiteljska drevesa azijskega kozlička so se izkazale različne vrste javorov, brez, vrb, divjega kostanja, jesenov in jelš.

Zadnji del predavanja je zajemal predstavitev postopka nadzora pri uvozu blaga, ki je opremljen z LPM, v Avstriji. Predavatelj nam je predstavil, kako ob vstopu takega blaga $\mathrm{v}$ Avstrijo poteka celoten postopek pregleda LPM, poleg tega pa smo spoznali tudi nekatere vrste, ki so jih našli v LPM, ki je spremljal pošiljke s Kitajske, in simptome, ki so ključni za odkrivanje teh vrst v LPM. Za razliko od Slovenije, Avstrija nima EU vstopnih točk, zato preiskovanje takih pošiljk poteka na posebnih inšpekcijskih mestih, ki morajo izpolnjevati stroge predpisane pogoje. Avstrija ima tudi več fitosanitarnih inšpektorjev, ki so zadolženi izključno za nadzor

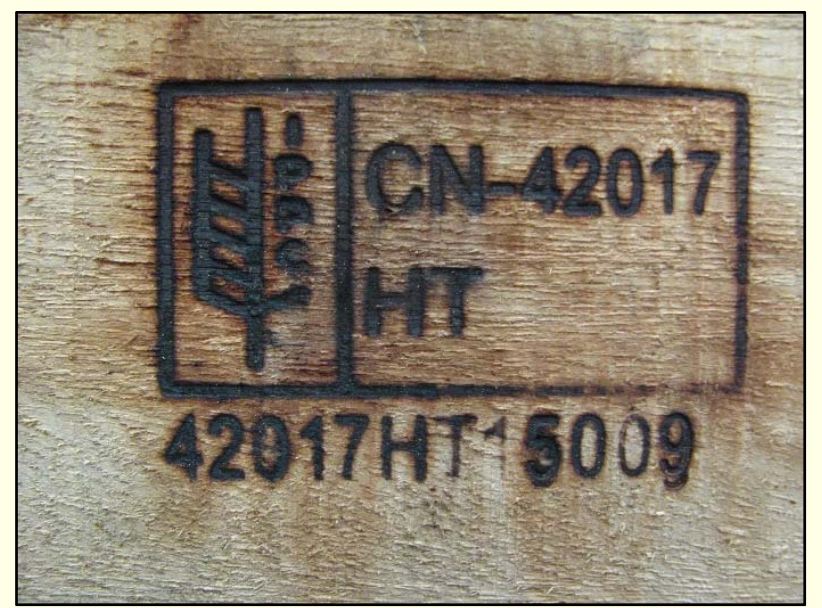

Slika 1: Uradna oznaka, ki potrjuje, da je bil LPM obdelan v skladu z mednarodnim standardom ISPM-15 (International Standards for Phytosanitary Measures No. 15). Sestavni deli oznake so: IPPC logotip (skrajno levo), ISO koda države (CN - Kitajska), registrska številka proizvajalca (42017), okrajšava načina obdelave LPM (HT - toplotna obdelava, DH - toplotna dielektrična obdelava, MB - zaplinjevanje z metilbromidom). Oznaka je uniformiran in mednarodno razpoznaven način uradnega potrjevanja, ki ne zahteva dodatnih dokumentov (foto: A. Kavčič) pošiljk, ki jih spremlja LPM, poleg tega pa pri preiskovanju LPM redno uporabljajo posebej trenirane službene pse.

Dopoldanskemu teoretičnemu delu je popoldne sledil praktični prikaz fitosanitarnega pregleda LPM z uporabo psa. Prikaz je potekal v Pragerskem v Kamnoseštvu Žunko d.o.o., ki se ukvarja z uvozom in prodajo kamna in različnega kamnitega materiala. Prikaz je izvedel g. Christof Schweiger, prav tako z Zveznega urada za gozdove Avstrije, s svojo triletno psičko, ki je izšolana posebej za iskanje karantenskih vrst kozličkov iz rodu Anoplophora.

Ob koncu dneva smo se udeleženci strinjali, da je bila delavnica o nadzoru LPM poučna in zanimiva, na kar je kazalo tudi živahno vključevanje udeležencev v diskusijo s predavatelji med in po predavanjih. $\mathrm{Na}$ delavnici smo dobili vpogled $\mathrm{v}$ zakonodajo na področju nadzora LPM, spoznali aktualno problematiko ter bili seznanjeni s ključnimi novostmi na področju mednarodnih standardov. Kar pa je najpomembneje, dobili smo praktične informacije strokovnjakov iz prve roke. Tovrstne delavnice so pomemben način pridobivanja novega znanja in priložnost za izmenjavo mnenj, zato so takšna izobraževanja dobrodošla tudi v prihodnje.

Vabimo vas, da si ogledate predstavitve $\mathrm{z}$ delavnice na spletnem portalu za varstvu gozdov. Povezava: http://www.zdravgozd.si/dogodki.aspx?iddogodek=11

*Gozdarski inštitut Slovenije, Večna pot 2, 1000 Ljubljana andreja.kavcic@gozdis.si 


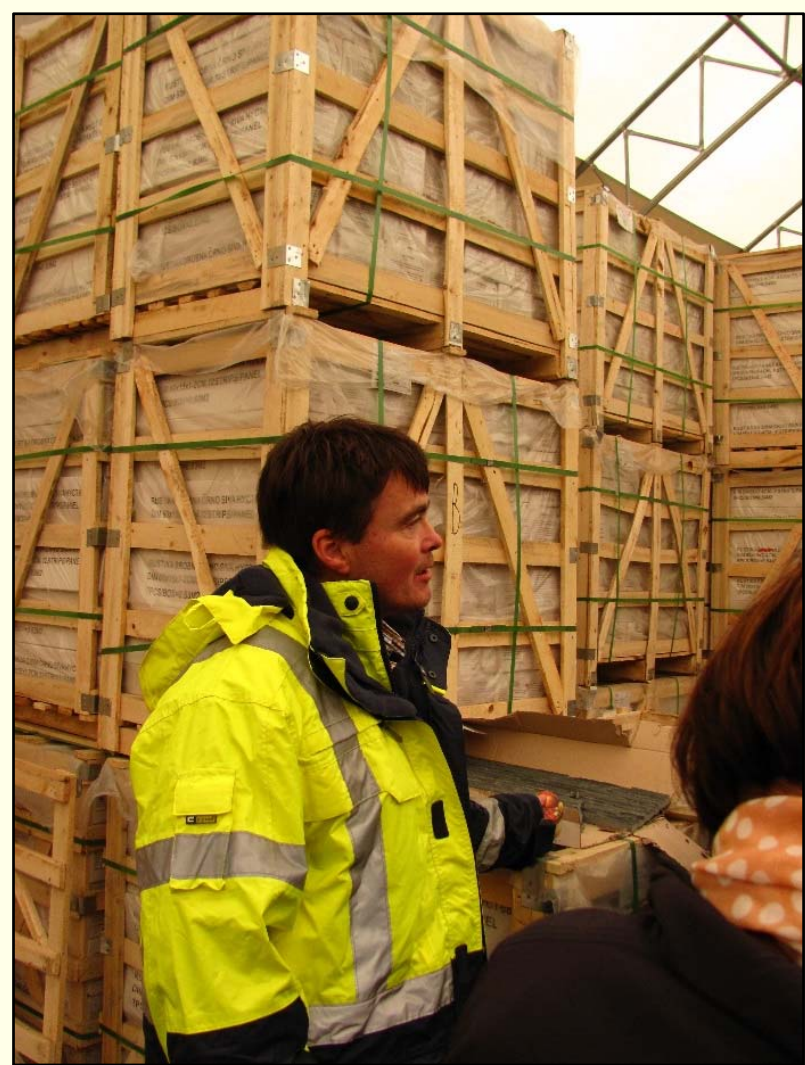

Slika 2: Predavatelj g. Hannes Krehan. (foto: A. Kavčič)

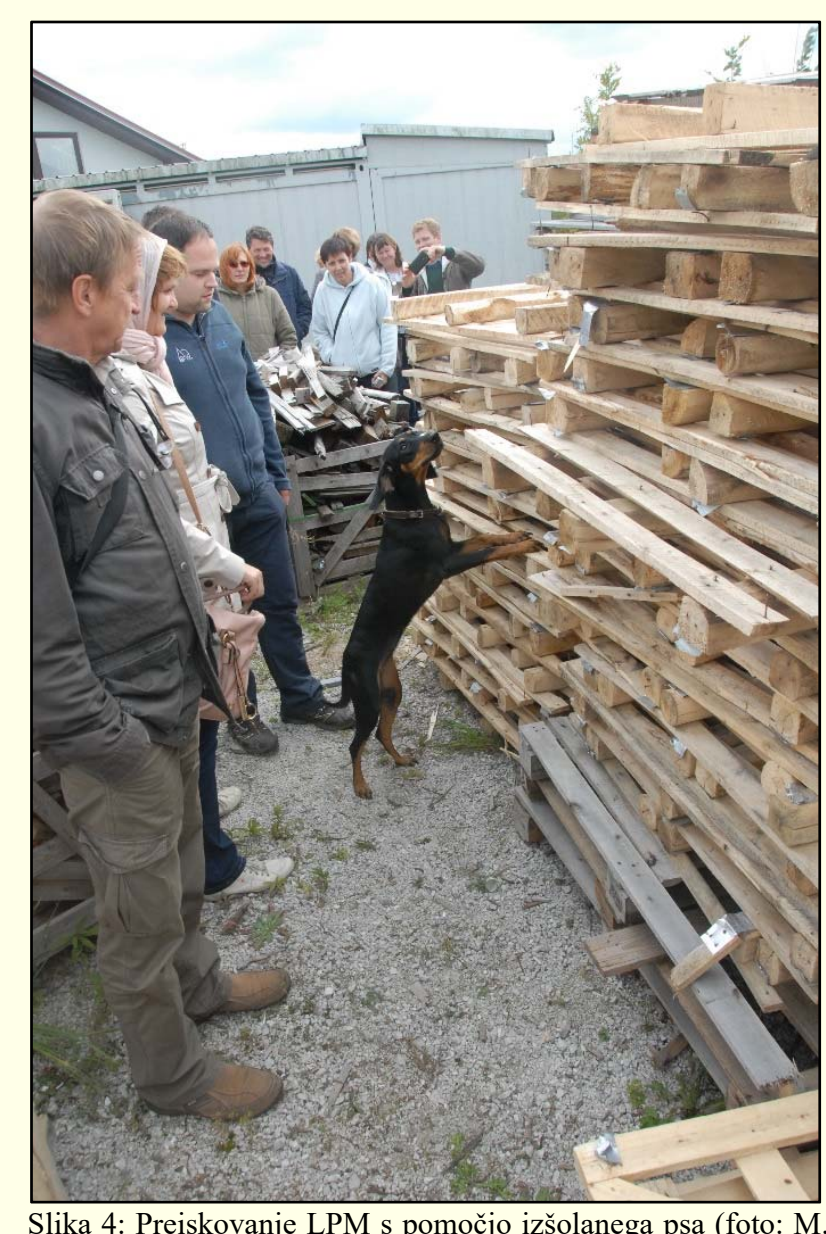

Slika 4: Preiskovanje LPM s pomočjo izšolanega psa (foto: M. de Groot)

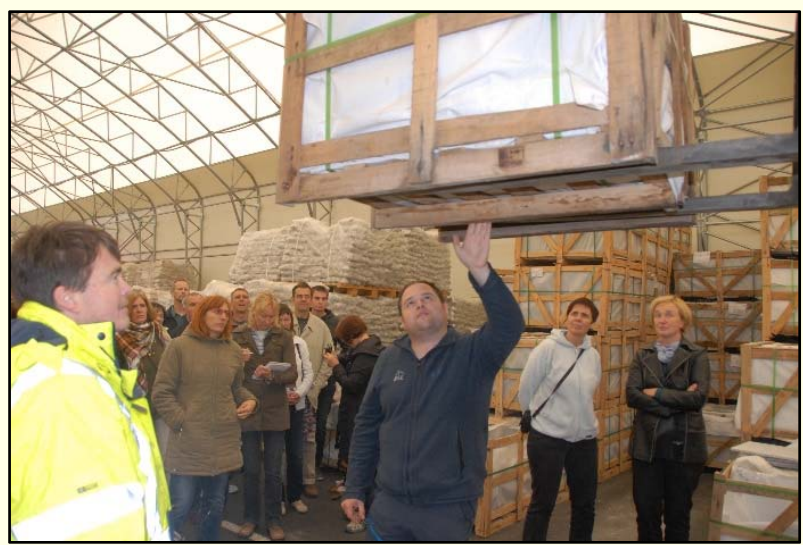

Slika 3: Vizualno pregledovanje LPM (foto: M. de Groot) 